Article

\title{
Plasma 25-Hydroxyvitamin D Concentrations are Associated with Polyunsaturated Fatty Acid Metabolites in Young Children: Results from the Vitamin D Antenatal Asthma Reduction Trial
}

\author{
Mengna Huang ${ }^{1}$, Rachel S. Kelly ${ }^{1} \mathbb{1}$, Priyadarshini Kachroo ${ }^{1}$, Su H. Chu ${ }^{1}{ }^{\circledR}$, \\ Kathleen Lee-Sarwar ${ }^{1,2}{ }^{\oplus}$, Bo L. Chawes ${ }^{3}{ }^{\circledR}$, Hans Bisgaard ${ }^{3}$, Augusto A. Litonjua ${ }^{4} \oplus$, \\ Scott T. Weiss ${ }^{1}$ (D) and Jessica Lasky-Su ${ }^{1, *}$ \\ 1 Channing Division of Network Medicine, Department of Medicine, Brigham and Women's Hospital and \\ Harvard Medical School, Boston, MA 02115, USA; mengna.huang@channing.harvard.edu (M.H.); \\ rachel.kelly@channing.harvard.edu (R.S.K.); priyadarshini.kachroo@channing.harvard.edu (P.K.); \\ su.chu@channing.harvard.edu (S.H.C.); klee-sarwar@bwh.harvard.edu (K.L.-S.); \\ scott.weiss@channing.harvard.edu (S.T.W.) \\ 2 Division of Rheumatology, Immunology and Allergy, Brigham and Women's Hospital and Harvard \\ Medical School, Boston, MA 02115, USA \\ 3 Copenhagen Prospective Studies on Asthma in Childhood (COPSAC), Herlev and Gentofte Hospital, \\ University of Copenhagen, 2820 Copenhagen, Denmark; chawes@copsac.com (B.L.C.); \\ bisgaard@copsac.com (H.B.) \\ 4 Division of Pediatric Pulmonary Medicine, Department of Pediatrics, Golisano Children's Hospital at Strong, \\ University of Rochester Medical Center, Rochester, NY 14642, USA; Augusto_Litonjua@urmc.rochester.edu \\ * Correspondence: jessica.su@channing.harvard.edu
}

Received: 9 March 2020; Accepted: 11 April 2020; Published: 14 April 2020

check for updates

\begin{abstract}
Vitamin D deficiency contributes to a multitude of health conditions, but its biological mechanisms are not adequately understood. Untargeted metabolomics offers the opportunity to comprehensively examine the metabolic profile associated with variations in vitamin D concentrations. The objective of the current analysis was to identify metabolites and metabolic pathways associated with plasma 25-hydroxyvitamin D [25(OH)D] concentrations. The current study included children of pregnant women in the Vitamin D Antenatal Asthma Reduction Trial, who had 25(OH)D and global metabolomics data at age 1 and 3 years. We assessed the cross-sectional associations between individual metabolites and $25(\mathrm{OH}) \mathrm{D}$ using linear regression adjusting for confounding factors. Twelve metabolites were significantly associated with plasma $25(\mathrm{OH}) \mathrm{D}$ concentrations at both age 1 and 3 after correction for multiple comparisons, including three members of the n-6 polyunsaturated fatty acid (PUFA) metabolism pathway (linoleate, arachidonate, and docosapentaenoate) inversely associated with $25(\mathrm{OH}) \mathrm{D}$. These PUFAs along with four other significant metabolites were replicated in the independent Childhood Asthma Management Program (CAMP) cohort. Both vitamin D and n-6 PUFAs are involved in inflammatory processes, and evidence from cell and animal studies demonstrate a plausible biological mechanism where the active form of 25(OH)D may influence n-6 PUFA metabolism. These relationships warrant further investigation in other populations.
\end{abstract}

Keywords: metabolomic epidemiology; vitamin D; 25-hydroxyvitamin D; polyunsaturated fatty acids; n-6 polyunsaturated fatty acids; Vitamin D Antenatal Asthma Reduction Trial (VDAART) 


\section{Introduction}

Apart from its classic function in calcium homeostasis and bone health [1,2], vitamin D is an important regulator of the immune system, acting in both innate and adaptive immunity [2,3]. This is partially evidenced by the fact that vitamin D receptors are expressed by many types of immune cells, where circulating 25-hydroxyvitamin $\mathrm{D}[25(\mathrm{OH}) \mathrm{D}]$ can be converted to its active form 1,25-dihydroxyvitamin $\mathrm{D}\left[1,25(\mathrm{OH})_{2} \mathrm{D}\right]$ locally [4]. Circulating concentrations of $25(\mathrm{OH}) \mathrm{D}$ are generally considered the most reliable biochemical marker of vitamin D status in epidemiologic studies, reflecting both vitamin D obtained through diet and vitamin D synthesized in the skin after exposure to ultraviolet sunlight $[1,5]$. Despite the importance of maintaining a sufficient vitamin D concentration, deficiency in vitamin D remains widespread across the world [3].

Vitamin D is thought to be involved in many immune and chronic inflammatory diseases: low concentrations of circulating vitamin D have been linked to increased risk of asthma and allergy $[3,6]$, autoimmune diseases [2], cardio-metabolic health [7,8], and cancer [9]. For asthma-related phenotypes, vitamin D supplementation during pregnancy has been shown to be protective against offspring asthma or persistent wheezing by age 3 [10]. A recent randomized controlled trial in preterm black infants suggested that postnatal supplementation may be important in decreasing risk of recurrent wheezing by age 1 year [11]. Vitamin D supplementation may also decrease the rate of asthma exacerbations [12]. Several lines of evidence support a mechanistic role of vitamin D in different endotypes of asthma [13].

Untargeted metabolomics is a high-throughput technology whereby large amounts of small molecules in a biospecimen can be characterized and quantified for their relative abundances [14], which may serve as a useful tool to gain a more comprehensive understanding of the biochemical pathways involved in the multifaceted functions of vitamin D. Previous investigations have examined metabolites associated with vitamin D status predominantly in adults $[15,16]$ and populations with existing health conditions [17-19]. There is a need for studies targeting the earliest life course prior to development of diseases, where vitamin D concentrations may influence pathogenesis.

Vitamin D status during infancy and early life are of particular importance as the development of the immune system occurs both prenatally and in the first years of life, and has lifelong impact on an individual's health [20]. Therefore, within the existing structure of the Vitamin D Antenatal Asthma Reduction Trial (VDAART), which randomized pregnant women to receive either 4400 or 400 IU/day of vitamin D supplementation during pregnancy, untargeted metabolomic data were obtained from stored plasma samples of VDAART children collected at age 1 and age 3 . The objective of the current analysis was to identify metabolites and metabolic pathways that are associated with plasma $25(\mathrm{OH}) \mathrm{D}$ concentrations. Findings from this investigation may provide insight into the underlying mechanism of health conditions affected by altered vitamin D status.

\section{Results}

\subsection{Results from Age 1 Analysis}

Four hundred and sixty-nine children were measured for metabolomics at age 1, of whom 17 $(3.6 \%)$ were missing plasma $25(\mathrm{OH}) \mathrm{D}$ measurements, and two were further missing body mass index (BMI). As a result, a total of 450 children at age 1 had complete information and were included in the analysis (Table 1). The average plasma 25(OH)D concentration at age 1 was $29.6 \mathrm{ng} / \mathrm{mL}$ (standard deviation $(\mathrm{SD})=8.4 \mathrm{ng} / \mathrm{mL})$. One hundred and ninety-six $(43.5 \%)$ children had plasma $25(\mathrm{OH}) \mathrm{D}$ concentrations $>30 \mathrm{ng} / \mathrm{mL}$. Overall white children, non-Hispanic-or-Latino children, and those from the St. Louis site had lower plasma $25(\mathrm{OH}) \mathrm{D}$ concentrations. 
Table 1. Characteristics of VDAART children included in age 1 analysis.

\begin{tabular}{|c|c|c|c|c|}
\hline & $\begin{array}{c}\text { All Subjects }(n= \\
450)\end{array}$ & $\begin{array}{c}25(\mathrm{OH}) \mathrm{D} \leq 30 \\
\mathrm{ng} / \mathrm{mL}(\mathrm{n}=254)\end{array}$ & $\begin{array}{c}25(\mathrm{OH}) \mathrm{D}>30 \\
\mathrm{ng} / \mathrm{mL}(\mathrm{n}=196)\end{array}$ & $P$-Value ${ }^{1}$ \\
\hline $\begin{array}{c}\text { Age } 1 \text { 25(OH)D } \\
\text { ng/mL, mean (SD) }\end{array}$ & $29.6(10.3)$ & $23.2(5.2)$ & $38.0(9.3)$ & $<0.001$ \\
\hline $\begin{array}{l}\text { Age } 1 \mathrm{BMI} \mathrm{kg} / \mathrm{m}^{2}, \\
\text { mean }(\mathrm{SD})\end{array}$ & $17.4(2.2)$ & $17.4(1.9)$ & $17.4(2.5)$ & 0.796 \\
\hline Sex, n $(\%)$ & & & & 0.594 \\
\hline Female & $205(45.6)$ & $119(46.9)$ & $86(43.9)$ & \\
\hline Male & $245(54.4)$ & $135(53.1)$ & $110(56.1)$ & \\
\hline Race, n (\%) & & & & 0.043 \\
\hline African American & $221(49.1)$ & $126(49.6)$ & $95(48.5)$ & \\
\hline Other & $86(19.1)$ & $39(15.4)$ & $47(24.0)$ & \\
\hline White & $143(31.8)$ & $89(35.0)$ & $54(27.6)$ & \\
\hline Ethnicity, n (\%) & & & & 0.019 \\
\hline Hispanic or Latino & $160(35.6)$ & $78(30.7)$ & $82(41.8)$ & \\
\hline $\begin{array}{c}\text { Not Hispanic or } \\
\text { Latino }\end{array}$ & $290(64.4)$ & $176(69.3)$ & $114(58.2)$ & \\
\hline Study site, n (\%) & & & & 0.003 \\
\hline Boston & $140(31.1)$ & $71(28.0)$ & $69(35.2)$ & \\
\hline San Diego & $149(33.1)$ & $75(29.5)$ & $74(37.8)$ & \\
\hline St. Louis & $161(35.8)$ & $108(42.5)$ & $53(27.0)$ & \\
\hline $\begin{array}{l}\text { Season of blood } \\
\text { collection, } \mathrm{n}(\%)\end{array}$ & & & & 0.062 \\
\hline Spring & $124(27.6)$ & $59(23.2)$ & $65(33.2)$ & \\
\hline Summer & $108(24.0)$ & $63(24.8)$ & $45(23.0)$ & \\
\hline Fall & $106(23.6)$ & $69(27.2)$ & 37 (18.9) & \\
\hline Winter & $112(24.9)$ & $63(24.8)$ & $49(25.0)$ & \\
\hline $\begin{array}{l}\text { Asthma/wheeze by } \\
\text { age } 3, \mathrm{n}(\%)\end{array}$ & & & & 0.669 \\
\hline No & $309(68.7)$ & $177(69.7)$ & $132(67.3)$ & \\
\hline Yes & $141(31.3)$ & $77(30.3)$ & $64(32.7)$ & \\
\hline $\begin{array}{c}\text { Treatment (in } \\
\text { pregnancy), n (\%) }\end{array}$ & & & & 0.885 \\
\hline $\begin{array}{l}4400 \mathrm{IU} / \text { day } \\
\text { vitamin D }\end{array}$ & $229(50.9)$ & $126(49.6)$ & $95(48.5)$ & \\
\hline $\begin{array}{c}400 \mathrm{IU} / \text { day vitamin } \\
\text { D }\end{array}$ & $221(49.1)$ & $128(50.4)$ & $101(51.5)$ & \\
\hline
\end{tabular}

\footnotetext{
${ }^{1}$ Significance of difference was evaluated using chi-squared test for categorical variables and two-sample t-test for continuous variables. Abbreviations: BMI, body mass index; SD, standard deviation; VDAART, Vitamin D Antenatal Asthma Reduction Trial; 25(OH)D, 25-hydroxyvitamin D.
}

From the primary linear model, 19 out of 511 metabolites investigated had significant associations with plasma $25(\mathrm{OH}) \mathrm{D}$ concentration after Bonferroni correction $\left(P\right.$-value threshold $\left.=9.78 \times 10^{-5}\right)$, adjusting for sex, race, ethnicity, study site, age 1, BMI, season of blood collection, and asthma or recurrent wheezing status by age 3 . The smallest $P$-value was $1.93 \times 10^{-8}$ for the association between docosadienoate $(22: 2 \mathrm{n}-6)$ and $25(\mathrm{OH}) \mathrm{D}$, with a negative direction of effect (estimated $\beta$-coefficient $=-2.75$ ). Forty metabolites had $P$-values below the ENT80 (effective number of independent tests accounting for $80 \%$ variance) threshold $\left(8.27 \times 10^{-4}\right.$, for a complete list of results see Supplemental Table S1 in Supplementary File 2; for definition of ENT80 see Section 4.4.), of which all were inversely associated with $25(\mathrm{OH}) \mathrm{D}$ concentrations. With respect to the false discovery rate (FDR) criteria, 117 metabolites had Benjamini-Hochberg (BH) FDR [21] < 0.05, and 32 had Benjamini-Yekutieli (BY) FDR $[22]<0.05$. 


\subsection{Results from Age 3 Analysis}

Four hundred and eleven children were measured for metabolomics at age 3 , of whom three $(0.7 \%)$ were missing plasma 25(OH)D measurements, with another missing BMI information. Therefore, at age 3, 407 VDAART children were included in the analytical sample (Table 2). A much lower proportion of children at age $3(11.8 \%)$ had plasma $25(\mathrm{OH}) \mathrm{D}$ concentrations $>30 \mathrm{ng} / \mathrm{mL}$ compared to the age 1 samples; the average plasma 25(OH)D concentration was also lower [20.8 $(\mathrm{SD}=8.4) \mathrm{ng} / \mathrm{mL}]$. Overall, African American children and those from the St. Louis and Boston sites had lower mean plasma $25(\mathrm{OH}) \mathrm{D}$ concentrations.

Table 2. Characteristics of VDAART children included in age 3 analysis.

\begin{tabular}{|c|c|c|c|c|}
\hline & $\begin{array}{l}\text { All Subjects } \\
(\mathrm{n}=407)\end{array}$ & $\begin{array}{c}25(\mathrm{OH}) \mathrm{D} \leq 30 \mathrm{ng} / \mathrm{mL} \\
(\mathrm{n}=359)\end{array}$ & $\begin{array}{c}25(\mathrm{OH}) \mathrm{D}>30 \mathrm{ng} / \mathrm{mL} \\
(\mathrm{n}=48)\end{array}$ & $P$-Value ${ }^{1}$ \\
\hline Age 3 25(OH)D ng/mL, mean (SD) & $20.8(8.4)$ & $18.7(6.3)$ & $36.3(6.1)$ & $<0.001$ \\
\hline Age $3 \mathrm{BMI} \mathrm{kg} / \mathrm{m}^{2}$, mean (SD) & $16.7(1.9)$ & $16.7(1.9)$ & $16.5(1.5)$ & 0.390 \\
\hline Sex, $\mathrm{n}(\%)$ & & & & 0.243 \\
\hline Female & $189(46.4)$ & $171(47.6)$ & $18(37.5)$ & \\
\hline Male & $218(53.6)$ & $188(52.4)$ & $30(62.5)$ & \\
\hline Race, n (\%) & & & & 0.002 \\
\hline African American & $197(48.4)$ & $185(51.5)$ & $12(25.0)$ & \\
\hline Other & $77(18.9)$ & $62(17.3)$ & $15(31.2)$ & \\
\hline White & $133(32.7)$ & $112(31.2)$ & $21(43.8)$ & \\
\hline Ethnicity, n (\%) & & & & 0.097 \\
\hline Hispanic or Latino & $131(32.2)$ & $110(30.6)$ & $21(43.8)$ & \\
\hline Not Hispanic or Latino & $276(67.8)$ & $249(69.4)$ & $27(56.2)$ & \\
\hline Study site, n (\%) & & & & 0.020 \\
\hline Boston & $86(21.1)$ & $80(22.3)$ & $6(12.5)$ & \\
\hline San Diego & $140(34.4)$ & $115(32.0)$ & $25(52.1)$ & \\
\hline St. Louis & $181(44.5)$ & $164(45.7)$ & $17(35.4)$ & \\
\hline Season of blood collection, $\mathrm{n}(\%)$ & & & & 0.687 \\
\hline Spring & $86(21.1)$ & $75(20.9)$ & $11(22.9)$ & \\
\hline Summer & $114(28.0)$ & $98(27.3)$ & $16(33.3)$ & \\
\hline Fall & $140(34.4)$ & $127(35.4)$ & $13(27.1)$ & \\
\hline Winter & $67(16.5)$ & $59(16.4)$ & $8(16.7)$ & \\
\hline Asthma/wheeze by age $3, \mathrm{n}(\%)$ & & & & 1.000 \\
\hline No & $301(74.0)$ & $266(74.1)$ & $35(72.9)$ & \\
\hline Yes & $106(26.0)$ & $93(25.9)$ & $13(27.1)$ & \\
\hline Treatment (in pregnancy), n (\%) & & & & 1.000 \\
\hline $4400 \mathrm{IU} /$ day vitamin D & $208(51.1)$ & $183(51.0)$ & $25(52.1)$ & \\
\hline $400 \mathrm{IU} /$ day vitamin D & $199(48.9)$ & $176(49.0)$ & $23(47.9)$ & \\
\hline
\end{tabular}

${ }^{1}$ Significance of difference was evaluated using chi-squared test for categorical variables and two-sample t-test for continuous variables. Abbreviations: BMI, body mass index; SD, standard deviation; VDAART, Vitamin D Antenatal Asthma Reduction Trial; 25(OH)D, 25-hydroxyvitamin D.

From the primary linear model, 21 metabolites had significant associations with plasma $25(\mathrm{OH}) \mathrm{D}$ concentration after Bonferroni correction $\left(P\right.$-value threshold $\left.=9.78 \times 10^{-5}\right)$, adjusting for sex, race, ethnicity, study site, age 3, BMI, season of blood collection, and asthma or recurrent wheezing status by age 3 . The most significant finding was for $\gamma$-glutamylglycine, which was inversely associated with $25(\mathrm{OH}) \mathrm{D}$ concentrations (estimated $\beta$-coefficient $=-2.34, P$-value $=1.64 \times 10^{-8}$ ). Fifty-three metabolites had $P$-values below the ENT80 threshold $\left(9.67 \times 10^{-4}\right.$, for a complete list of results see Supplemental Table S2 in Supplementary File 2), of which 51 metabolites had negative associations, and two had positive associations with $25(\mathrm{OH}) \mathrm{D}$ concentrations. With respect to the FDR criteria, 128 metabolites had BH FDR $<0.05$, and 40 had BY FDR $<0.05$.

\subsection{Overlap between Age 1 and Age 3 Results}

We focused on metabolites passing their respective ENT80 thresholds when comparing results from the age 1 samples and those from the age 3 samples (Supplemental Figure S1, Supplementary 
File 1). A total of 12 metabolites were significantly associated with $25(\mathrm{OH}) \mathrm{D}$ concentration at both time points with the same direction of effect (ordered by age 1 result significance): docosapentaenoate $(22: 5 \mathrm{n}$-6 DPA $)\left(\right.$ age $1 P$-value $=9.74 \times 10^{-6}$, age $3 P$-value $\left.=6.47 \times 10^{-4}\right)$, glycine $($ age $1 P$-value $=3.03$ $\times 10^{-5}$, age $3 P$-value $\left.=8.89 \times 10^{-4}\right), 1$-palmitoyl-glycerophosphoethanolamine $(G P E)($ age $1 P$-value $=$ $4.22 \times 10^{-5}$, age $3 P$-value $\left.=4.29 \times 10^{-4}\right)$, serine $\left(\right.$ age $1 P$-value $=7.21 \times 10^{-5}$, age $3 P$-value $=9.43 \times$ $\left.10^{-4}\right), \mathrm{N}$-acetyltaurine (age $1 P$-value $=7.75 \times 10^{-5}$, age $3 P$-value $\left.=6.96 \times 10^{-4}\right), \mathrm{N}$-palmitoylglycine $\left(\right.$ age $1 P$-value $=1.23 \times 10^{-4}$, age $3 P$-value $\left.=9.27 \times 10^{-5}\right)$, sphingomyelin $(\mathrm{d} 18: 2 / 16: 0, \mathrm{~d} 18: 1 / 16: 1)($ age 1 $P$-value $=3.06 \times 10^{-4}$, age $3 P$-value $\left.=1.66 \times 10^{-4}\right)$, arachidonate $(20: 4 \mathrm{n}-6)\left(\right.$ age $1 P$-value $=3.10 \times 10^{-4}$, age $3 P$-value $\left.=6.20 \times 10^{-4}\right)$, palmitoyl-linoleoyl-glycerol $(16: 0 / 18: 2)\left(\right.$ age $1 P$-value $=5.83 \times 10^{-4}$, age 3 $P$-value $\left.=5.89 \times 10^{-4}\right)$, linoleate $\left(18: 2 \mathrm{n}\right.$-6) $\left(\right.$ age $1 P$-value $=7.23 \times 10^{-4}$, age $3 P$-value $\left.=4.70 \times 10^{-5}\right)$, hydroxyproline (age $1 P$-value $=7.38 \times 10^{-4}$, age $3 P$-value $\left.=5.06 \times 10^{-5}\right)$, and 1 -stearoyl-GPE $($ age 1 $P$-value $=7.44 \times 10^{-4}$, age $3 P$-value $\left.=6.57 \times 10^{-5}\right)$, all of which were inversely associated with $25(\mathrm{OH}) \mathrm{D}$ concentrations (Table 3). Taking n-6 DPA as an example, the results can be interpreted as follows: one standard deviation increase in $\log _{10} \mathrm{n}-6$ DPA was associated with an average of $1.40 \mathrm{ng} / \mathrm{mL}$ decrease in plasma $25(\mathrm{OH}) \mathrm{D}$ concentrations in VDAART children at age 3 , for those with the same sex, race, ethnicity, study site, BMI, season of blood collection, and asthma or recurrent wheezing status by age 3 .

Noting that three of the common significant metabolites were n-6 PUFAs in the linoleic acid metabolism pathway (linoleate, arachidonate, and docosapentaenoate; for an illustration of n- 6 and n-3 PUFA metabolism see Supplemental Figure S2, Supplementary File 1) [23,24]. Two additional members of this pathway, linolenate (18:3) and dihomo-linolenate (20:3), were also inversely associated with $25(\mathrm{OH}) \mathrm{D}$, although the assay was not able to distinguish between their n-3 and n-6 forms. Both were negatively associated with $25(\mathrm{OH}) \mathrm{D}$ concentration at age 1 and age 3 . Linolenate had a nominally significant association with plasma $25(\mathrm{OH}) \mathrm{D}$ concentrations at age $1\left(P\right.$-value $\left.=9.48 \times 10^{-3}\right)$, and was significantly associated with $25(\mathrm{OH}) \mathrm{D}$ concentration at age $3\left(P\right.$-value $=1.52 \times 10^{-4}$, below ENT80). Dihomo-linolenate had a $P$-value below ENT80 at age $1\left(P\right.$-value $\left.=4.40 \times 10^{-5}\right)$, and was nominally significantly associated with $25(\mathrm{OH}) \mathrm{D}$ concentrations at age $3\left(P\right.$-value $\left.=1.48 \times 10^{-3}\right)$.

\subsection{Sensitivity Analysis Results}

Using Rosner's outlier test [25], we identified six children at age 1 and one child at age 3 who were outliers in vitamin D distribution with concentrations much higher than others (Supplemental Figure S3 and S4, Supplementary File 1). We repeated the analyses after removing these outlying subjects, and the results were not substantially changed. Eleven metabolites were significantly associated with 25(OH)D concentrations at both time points with the same direction of effect (Table 4), including eight in Table 3. Based on their respective ENT80 thresholds, dihomo-linolenate (20:3) became significantly associated with $25(\mathrm{OH}) \mathrm{D}$ concentrations at both age $1\left(P\right.$-value $\left.=1.60 \times 10^{-5}\right)$ and age $3(P$-value $=$ $\left.8.10 \times 10^{-4}\right)$. Two additional metabolites were significant based on ENT80: linoleoyl ethanolamide and valylglycine, while sphingomyelin (d18:2/16:0, d18:1/16:1), 1-stearoyl-GPE, hydroxyproline, and palmitoyl-linoleoyl-glycerol (16:0/18:2) failed to retain significance. Removing asthma or recurrent wheezing status by age 3 from the linear models, or adding a maternal treatment group, did not substantially change the results (Supplemental Table S3, Supplementary File 2). We did not observe substantial differences in characteristics comparing children included in the analyses with those not included, except for the study site in the age 3 sample (Supplemental Table S4 and S5, Supplementary File 2), which was adjusted for in our regression models. 
Table 3. Plasma metabolites significantly associated with 25(OH)D concentrations common to age 1 and 3 samples based on ENT80 thresholds 1.

\begin{tabular}{|c|c|c|c|c|c|c|c|}
\hline \multirow{2}{*}{ Metabolite } & \multirow{2}{*}{ Pathway } & \multicolumn{3}{|c|}{ Age 1 Result ${ }^{2}$} & \multicolumn{3}{|c|}{ Age 3 Result $^{3}$} \\
\hline & & $\hat{\beta}$ & $P$-Value & $95 \%$ CI & $\hat{\beta}$ & $P$-Value & $95 \% \mathrm{CI}$ \\
\hline docosapentaenoate (n-6 DPA; 22:5) & Long Chain PUFA & -2.27 & $9.74 \times 10^{-6}$ & $(-3.27,-1.27)$ & -1.40 & $6.47 \times 10^{-4}$ & $(-2.20,-0.60)$ \\
\hline glycine & Glycine, Serine and Threonine Metabolism & -2.06 & $3.03 \times 10^{-5}$ & $(-3.02,-1.10)$ & -1.33 & $8.89 \times 10^{-4}$ & $(-2.11,-0.55)$ \\
\hline 1-palmitoyl-GPE (16:0) & Lysophospholipid & -2.00 & $4.22 \times 10^{-5}$ & $(-2.95,-1.05)$ & -1.42 & $4.29 \times 10^{-4}$ & $(-2.20,-0.63)$ \\
\hline serine & Glycine, Serine and Threonine Metabolism & -1.96 & $7.21 \times 10^{-5}$ & $(-2.92,-1.00)$ & -1.32 & $9.43 \times 10^{-4}$ & $(-2.11,-0.54)$ \\
\hline $\mathrm{N}$-acetyltaurine & Methionine, Cysteine, SAM and Taurine Metabolism & -1.95 & $7.75 \times 10^{-5}$ & $(-2.90,-0.99)$ & -1.36 & $6.96 \times 10^{-4}$ & $(-2.15,-0.58)$ \\
\hline $\mathrm{N}$-palmitoylglycine & Fatty Acid Metabolism (Acyl Glycine) & -1.91 & $1.23 \times 10^{-4}$ & $(-2.88,-0.94)$ & -1.57 & $9.27 \times 10^{-5}$ & $(-2.36,-0.79)$ \\
\hline sphingomyelin (d18:2/16:0, d18:1/16:1) & Sphingomyelins & -1.80 & $3.06 \times 10^{-4}$ & $(-2.77,-0.83)$ & -1.52 & $1.66 \times 10^{-4}$ & $(-2.31,-0.74)$ \\
\hline arachidonate $(20: 4 n-6)$ & Long Chain PUFA & -1.78 & $3.10 \times 10^{-4}$ & $(-2.74,-0.82)$ & -1.40 & $6.20 \times 10^{-4}$ & $(-2.19,-0.60)$ \\
\hline palmitoyl-linoleoyl-glycerol (16:0/18:2) & Diacylglycerol & -1.68 & $5.83 \times 10^{-4}$ & $(-2.64,-.073)$ & -1.38 & $5.89 \times 10^{-4}$ & $(-2.16,-0.60)$ \\
\hline linoleate $(18: 2 n-6)$ & Long Chain PUFA & -1.65 & $7.23 \times 10^{-4}$ & $(-2.60,-0.70)$ & -1.65 & $4.70 \times 10^{-5}$ & $(-2.44,-0.86)$ \\
\hline hydroxyproline & Urea cycle; Arginine and Proline Metabolism & -1.75 & $7.38 \times 10^{-4}$ & $(-2.77,-0.74)$ & -1.67 & $5.06 \times 10^{-5}$ & $(-2.47,-0.87)$ \\
\hline 1-stearoyl-GPE (18:0) & Lysophospholipid & -1.65 & $7.44 \times 10^{-4}$ & $(-2.61,-0.70)$ & -1.57 & $6.57 \times 10^{-5}$ & $(-2.34,-0.81)$ \\
\hline
\end{tabular}

${ }^{1}$ The $P$-value thresholds for declaring significance were $8.27 \times 10^{-4}$ in age 1 analysis and $9.67 \times 10^{-4}$ in age 3 analysis. ${ }^{2,3}$ Linear models adjusted for sex, race, ethnicity, study site, BMI at respective age, season of blood collection, and asthma or recurrent wheezing status by age 3. Abbreviations: $\hat{\beta}$, estimated effect; CI, confidence interval; ENT, effective number of independent tests; GPE, glycerophosphoethanolamine; PUFA, polyunsaturated fatty acid; SAM, S-adenosyl methionine; 25(OH)D, 25-hydroxyvitamin D.

Table 4. Plasma metabolites significantly associated with $25(\mathrm{OH}) \mathrm{D}$ concentrations common to age 1 and 3 samples based on ENT80 thresholds ${ }^{1}$ after excluding outliers in $25(\mathrm{OH}) \mathrm{D}$ distribution at respective time points.

\begin{tabular}{|c|c|c|c|c|c|c|c|}
\hline \multirow{2}{*}{ Metabolite } & \multirow{2}{*}{ Pathway } & \multicolumn{3}{|c|}{ Age 1 Result ${ }^{2}$} & \multicolumn{3}{|c|}{ Age 3 Result $^{3}$} \\
\hline & & $\hat{\beta}$ & $P$-Value & $95 \%$ CI & $\hat{\beta}$ & $P$-Value & $95 \%$ CI \\
\hline $\mathrm{N}$-acetyltaurine & Methionine, Cysteine, SAM and Taurine Metabolism & -1.90 & $7.01 \times 10^{-6}$ & $(-2.72,-1.08)$ & -1.37 & $4.05 \times 10^{-4}$ & $(-2.13,-0.62)$ \\
\hline docosapentaenoate (n-6 DPA; 22:5) & Long Chain PUFA & -1.91 & $1.29 \times 10^{-5}$ & $(-2.77,-1.06)$ & -1.40 & $4.28 \times 10^{-4}$ & $(-2.17,-0.62)$ \\
\hline dihomo-linolenate ( $20: 3 n-3$ or $n-6)$ & Long Chain PUFA & -1.88 & $1.60 \times 10^{-5}$ & $(-2.72,-1.03)$ & -1.33 & $8.10 \times 10^{-4}$ & $(-2.11,-0.56)$ \\
\hline glycine & Glycine, Serine and Threonine Metabolism & -1.64 & $1.05 \times 10^{-4}$ & $(-2.46,-0.82)$ & -1.38 & $3.67 \times 10^{-4}$ & $(-2.13,-0.62)$ \\
\hline arachidonate $(20: 4 n-6)$ & Long Chain PUFA & -1.62 & $1.13 \times 10^{-4}$ & $(-2.44,-0.80)$ & -1.34 & $6.58 \times 10^{-4}$ & $(-2.12,-0.57)$ \\
\hline linoleate $(18: 2 n-6)$ & Long Chain PUFA & -1.56 & $1.79 \times 10^{-4}$ & $(-2.37,-0.75)$ & -1.63 & $3.14 \times 10^{-5}$ & $(-2.39,-0.87)$ \\
\hline serine & Glycine, Serine and Threonine Metabolism & -1.59 & $1.87 \times 10^{-4}$ & $(-2.41,-0.76)$ & -1.30 & $7.74 \times 10^{-4}$ & $(-2.05,-0.55)$ \\
\hline N-palmitoylglycine & Fatty Acid Metabolism (Acyl Glycine) & -1.50 & $4.28 \times 10^{-4}$ & $(-2.34,-0.67)$ & -1.65 & $2.21 \times 10^{-5}$ & $(-2.40,-0.89)$ \\
\hline 1-palmitoyl-GPE (16:0) & Lysophospholipid & -1.47 & $5.11 \times 10^{-4}$ & $(-2.29,-0.64)$ & -1.53 & $8.81 \times 10^{-5}$ & $(-2.28,-0.77)$ \\
\hline linoleoyl ethanolamide & Endocannabinoid & -1.43 & $6.57 \times 10^{-4}$ & $(-2.25,-0.61)$ & -1.29 & $9.53 \times 10^{-4}$ & $(-2.06,-0.53)$ \\
\hline valylglycine & Dipeptide & -1.44 & $6.59 \times 10^{-4}$ & $(-2.26,-0.61)$ & -1.81 & $4.43 \times 10^{-6}$ & $(-2.57,-1.04)$ \\
\hline
\end{tabular}

1 The $P$-value thresholds for declaring significance were $8.27 \times 10^{-4}$ in age 1 analysis and $9.67 \times 10^{-4}$ in age 3 analysis. ${ }^{2,3}$ Linear models adjusted for sex, race, ethnicity, study site, BMI at respective age, season of blood collection, and asthma or recurrent wheezing status by age 3 . Abbreviations: $\hat{\beta}$, estimated effect; CI, confidence interval; ENT, effective number of independent tests; GPE, glycerophosphoethanolamine; PUFA, polyunsaturated fatty acid; SAM, S-adenosyl methionine; 25(OH)D, 25-hydroxyvitamin D. 


\subsection{Pathway Analysis Results}

We used the web-based tool MetaboAnalyst 4.0 to perform pathway analysis of the significant metabolites ( $P$-values below ENT80, for details see Materials and Methods Section 4.4.) [26]. In the age 1 samples, the arachidonic acid metabolism pathway was nominally significantly over-represented $\left(P\right.$-value $\left.=1.89 \times 10^{-2}\right)$, while the linoleic acid metabolism pathway had the highest pathway impact (Figure 1). Four pathways were nominally significantly over-represented among the 53 metabolites that were significant in the age 3 samples: linoleic acid metabolism $\left(P\right.$-value $\left.=1.15 \times 10^{-2}\right)$, arachidonic acid metabolism $\left(P\right.$-value $\left.=1.28 \times 10^{-2}\right)$, glycerophospholipid metabolism $\left(P\right.$-value $\left.=1.75 \times 10^{-2}\right)$, and methane metabolism $\left(P\right.$-value $\left.=3.57 \times 10^{-2}\right)$, with the highest impacts as reflected in the significance against pathway impact plot (Figure 2). Overall, the n-6 PUFA pathways, namely the linoleic acid metabolism and arachidonic acid metabolism pathways, appeared to have high impact in pathway topology analysis, and were largely over-represented in terms of association with plasma $25(\mathrm{OH}) \mathrm{D}$ concentrations.

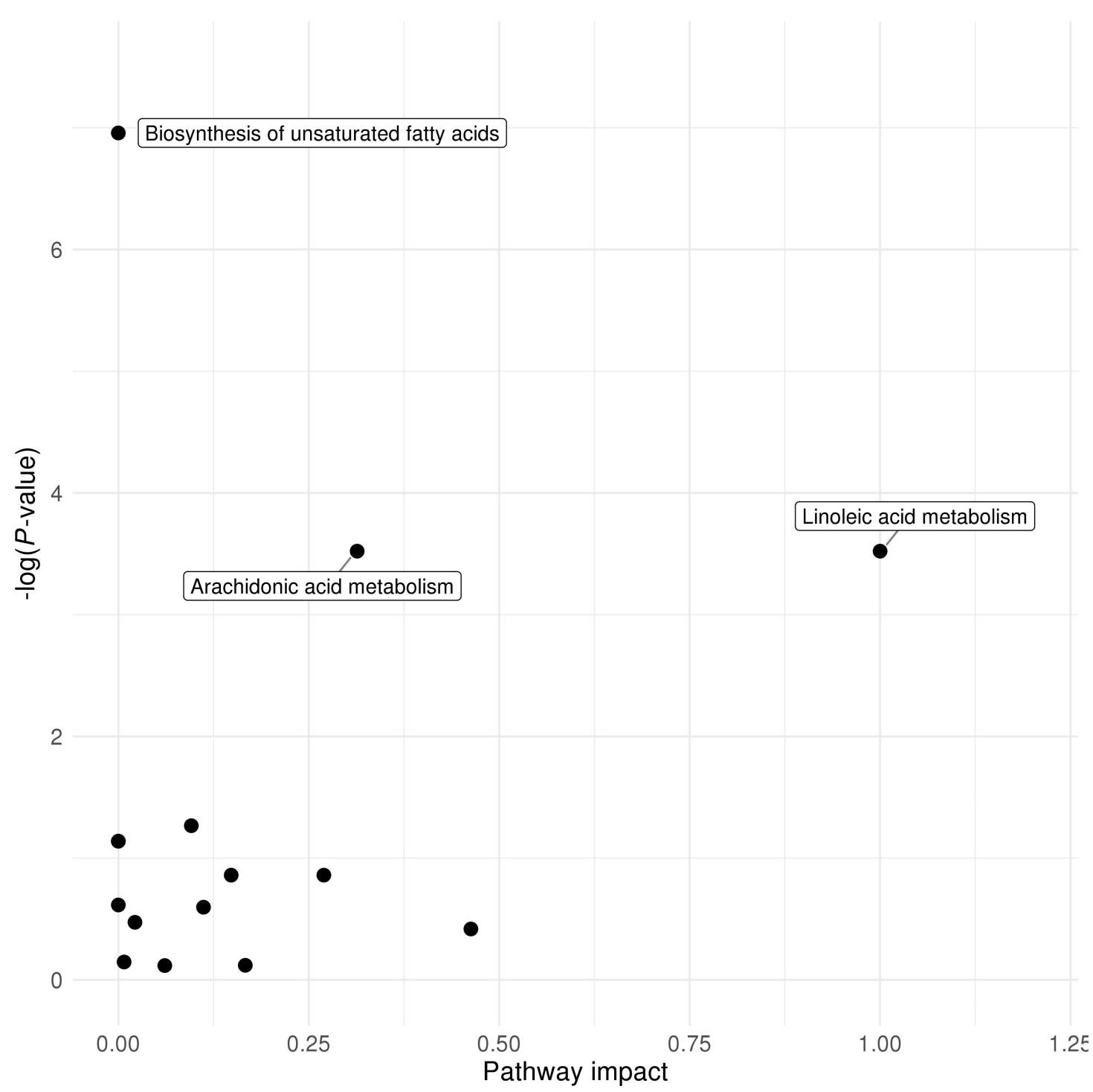

Figure 1. Pathway over-representation analysis significance against pathway impact plot for MetaboAnalyst pathway analysis results at age 1 (natural logarithm of $P$-value on Y-axis). 


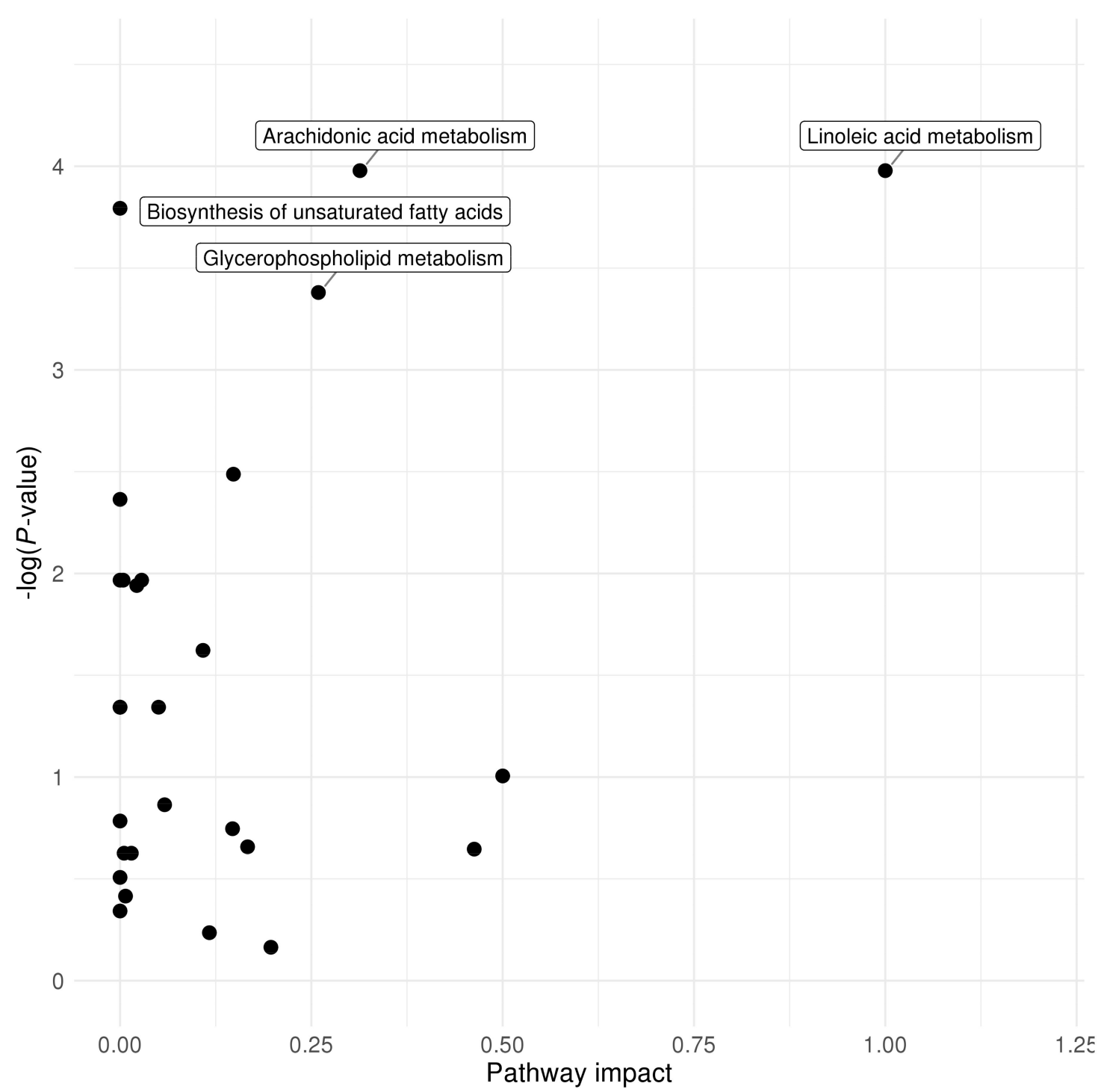

Figure 2. Pathway over-representation analysis significance against pathway impact plot for MetaboAnalyst pathway analysis results at age 3 (natural logarithm of $P$-value on Y-axis).

\subsection{Replication Analysis Results}

We replicated our analysis in the Childhood Asthma Management Program (CAMP) [27] as described in Materials and Methods Section 4.5. Characteristics of CAMP children are summarized in Supplemental Table S6 and S7 in Supplementary File 2. Among the n-6 PUFAs measured in VDAART, four were relatively quantified in CAMP: linoleate, arachidonate, docosapentaenoate, and $\gamma$-linolenate (distinguished from the $\mathrm{n}-3 \alpha$ form). Four other metabolites that were significant in VDAART at ages 1 and 3 were available for replication in CAMP. None of the associations with serum 25(OH)D were nominally significant at CAMP baseline. However, at the end of the trial all four n-6 PUFAs were negatively associated with 25(OH)D (same direction of estimated effects as in VDAART) with high significance: $\gamma$-linolenate $P$-value $=1.58 \times 10^{-4}$, linoleate $P$-value $=1.65 \times 10^{-4}$, docosapentaenoate $P$-value $=1.01 \times 10^{-3}$, and arachidonate $P$-value $=6.10 \times 10^{-3}$. We were also able to replicate the associations with serum $25(\mathrm{OH}) \mathrm{D}$ at the end of the CAMP trial for glycine $\left(P\right.$-value $\left.=7.43 \times 10^{-8}\right)$, serine $\left(P\right.$-value $\left.=3.52 \times 10^{-7}\right)$, hydroxyproline $\left(P\right.$-value $\left.=2.62 \times 10^{-5}\right)$, and linoleoyl ethanolamide $\left(P\right.$-value $\left.=7.18 \times 10^{-4}\right)$, with the same directions of effect as in VDAART (Supplemental Table S8 in Supplementary File 2). 


\section{Discussion}

In the current study, we characterized early life plasma metabolomic profiles associated with $25(\mathrm{OH}) \mathrm{D}$ status at two time points in children of diverse racial/ethnic backgrounds. From individual-metabolite analyses, we identified twelve metabolites that were associated with $25(\mathrm{OH}) \mathrm{D}$ at both age 1 and age 3 after multiple testing correction with the ENT-based approach. Among these metabolites, three members of the n-6 long chain PUFA metabolism pathway (linoleate, arachidonate and docosapentaenoate) were replicated in CAMP, an independent cohort of older children with asthma [28]. The association between four other metabolites and 25(OH)D were also replicated. These results were further corroborated by pathway analysis where we observed high significance and/or high impact of the linoleic acid metabolism and arachidonic acid metabolism pathways.

To our knowledge, this analysis was the first to characterize the metabolic profile of $25(\mathrm{OH}) \mathrm{D}$ concentrations at two time points in early life, with replication of the main findings in an independent population of older children. Previous studies mostly focused on adult populations [15-17], had metabolomics data at one single time point [15-19], or were in subjects with specifically defined severe illness $[17,19]$. In a study of 30 pregnant adolescents where half had serum $25(\mathrm{OH}) \mathrm{D}$ concentrations $\geq 20 \mathrm{ng} / \mathrm{mL}$, Finkelstein et al. used a hierarchical mixture model to discern differences in the metabolomic profiles between low and high 25(OH)D groups, and higher leukotriene B4 levels were found to be associated with low 25(OH)D [18]. Leukotriene B4 is a downstream eicosanoid derivative of the n-6 PUFAs linoleic acid and arachidonic acid, and promotes the release of proinflammatory cytokines and reactive oxygen species (ROS) [23]. Our results for n-6 PUFAs were also consistent with findings from a recent animal study in which pregnant female rats were randomly assigned to a control or vitamin D deficient diet [29]. Compared to rats on a control diet, those on a vitamin D deficient diet had higher arachidonic acid concentrations in both plasma and liver, and higher n-6 DPA concentrations in plasma [29]. In a previous investigation in a smaller subgroup of VDAART children at age 3, Blighe et al. identified three clusters of children based on their metabolomic profiles, where the first cluster was characterized by high concentrations of fatty acids including linoleate and linolenate (18:3n-3 or n-6), and were exposed to the lowest in utero vitamin D concentrations throughout pregnancy, while the third cluster had the opposite profile [30]. While the findings from this previous analysis identified metabolomic profiles consistent with the results presented here, they stemmed from different research questions analyzed with distinct statistical approaches, and the current analysis was based on a much larger sample size at age 3 and additional metabolomic data from another time point (age 1).

The observed inverse associations between $25(\mathrm{OH}) \mathrm{D}$ and $\mathrm{n}-6$ PUFAs in the plasma may be a reflection of the western lifestyle characterized by increased time spent indoors, sunscreen use [3], and dietary patterns with high intake of n-6 PUFAs [31]. Alternatively, a plausible mechanism has also been proposed where vitamin D can influence the metabolism of long chain PUFAs [32] (for an illustration see Supplemental Figure S5, Supplementary File 1). The n-6 PUFAs, linoleic acid and arachidonic acid are among the essential fatty acids that are important constituents of cell membrane phospholipids $[33,34]$. In cell culture studies, $1,25(\mathrm{OH})_{2} \mathrm{D}$ has been shown to induce gene expression of cystathionine $\beta$-synthase, which metabolizes and clears homocysteine via the transsulfuration pathway [35]. Homocysteine can function as an inducer of arachidonic acid release from the membrane and accumulation of its downstream eicosanoid and ROS [36]. In human serum samples, a recent study used metabolite set enrichment analysis to identify arachidonic acid and linoleic acid metabolism as the two pathways with significant differences comparing high- and low-homocysteine groups [37]. $1,25(\mathrm{OH})_{2} \mathrm{D}$ may also downregulate the expression of cyclooxygenase-2 (COX-2) [38], which is an enzyme that metabolizes arachidonic acid into 2-series prostaglandins and thromboxanes [23]. This suggests that high concentrations of vitamin D may help mitigate the pro-inflammatory effect of n-6 PUFAs. This anti-inflammatory pathway effect of vitamin D may in part be responsible for the reduced risk of asthma or recurrent wheezing seen in our previous pregnancy vitamin D trials [10], as arachidonic acid and its downstream eicosanoids are key in asthma airway inflammation [39]. 
Among metabolites of arachidonic acid, increased production of 4-series leukotrienes has been observed in subsets of patients with bronchial asthma, through increased accumulation of arachidonic acid in cells recruited in asthmatic airways (mostly eosinophils) and enhanced activity and release of enzymes in the synthesis of these eicosanoids [40]. However, n-3 PUFAs may also act as a substrate for COX-2, which derive eicosanoids that are generally considered anti-inflammatory [23]. This was also observed in our recent trial, where pregnant women were supplemented in a $2 \times 2$ factorial design with high-dose vitamin D and n-3 long chain PUFA, showing borderline interaction between the two dietary interventions with respect to asthma or recurrent wheezing in the offspring [41]. The complex interplay between vitamin D and PUFA metabolism warrants more detailed investigation.

In a cross-sectional subsample of male smokers aged 50-69 years, Nelson et al. identified three metabolites related to fish consumption (3-carboxy-4-methyl-5-propyl-2-furanpropanoate (CMPF), eicosapentaenoate (EPA), and docosahexaenoate (DHA)) that were positively associated with serum 25(OH)D concentrations, while n-6 PUFAs did not reach nominal significance [16]. We observed inverse associations between plasma EPA or DHA and $25(\mathrm{OH}) \mathrm{D}$ concentrations at both age $1(P$-values $=$ $3.65 \times 10^{-4}$ and $1.48 \times 10^{-3}$ respectively) and age $3\left(P\right.$-values $=3.80 \times 10^{-1}$ and $7.84 \times 10^{-2}$ respectively), while the directions of effect for $C M P F$ were not consistent at the two time points (age 1 negative association $P$-value $=8.76 \times 10^{-3}$, age 3 positive association $P$-value $=2.27 \times 10^{-3}$ ). In the analysis by Nelson et al., N-acetyltaurine and 1-palmitoyl-GPE reached nominal significance and the directions of observed associations were consistent with ours. Vogt et al. discovered 30 metabolites associated with serum 25(OH)D concentrations [15], where summary measures of fatty acid unsaturation and $\mathrm{CMPF}$ were positively associated with $25(\mathrm{OH}) \mathrm{D}$. The discrepancy between our results and theirs may be due to the vastly different study populations included: children in early life and middle-aged to older adults have substantial differences in lifestyle factors that may influence metabolism. As such, our results may only be generalizable to children.

Several limitations in our study should be noted. First, not all VDAART children had metabolomics measured at ages 1 and 3 years. We checked for characteristics that might be different between children included in the respective analytical samples with those not included, and only study site at age 3 was significantly different, which was adjusted for in our statistical modeling. Moreover, neither 25(OH)D concentrations nor metabolite concentrations influenced whether a child was selected for metabolomic profiling, mitigating the potential of selection bias. Second, our analyses were cross-sectional, making it difficult to establish temporality and causality between $25(\mathrm{OH}) \mathrm{D}$ concentrations and the metabolites investigated. Third, although we had sufficient sample sizes at both ages, we were likely underpowered to perform subgroup analyses. We also recognize the differences in CAMP from VDAART as a replication cohort. Different analytical platforms were used to obtain metabolomics data in serum instead of plasma, and children in CAMP were older, recruited much earlier (in the 1990s), had higher 25(OH)D concentrations overall, and all had mild-to-moderate asthma. Despite these differences, we were still able to examine common metabolites measured by both platforms based on their biochemical identities, and replicate our main findings. Finally, although we accounted for several covariates that may confound or modify the relationship between plasma metabolites and $25(\mathrm{OH}) \mathrm{D}$ concentrations, we were not able to take into consideration unmeasured factors such as diet and physical activity in early life of VDAART children. These are prone to measurement errors during infancy and toddlerhood due to individual variability and subjectivity of caregivers [42]. To address unmeasured confounding as a broader issue in metabolomics epidemiology, statistical methods have been proposed involving, e.g., latent confounding factors [43], while no agreed-upon standard approach has been established. 


\section{Materials and Methods}

\subsection{Study Subjects}

The Vitamin D Antenatal Asthma Reduction Trial (VDAART) was a randomized, double-blind, placebo-controlled trial with parallel design conducted in three centers across the United States (ClinicalTrials.gov identifier: NCT00920621). The primary aim of the trial was to determine the effect of prenatal vitamin D supplementation on the incidence of asthma outcomes in the offspring. Detailed rationale, design, methods, and results of VDAART have been published elsewhere [44,45]. Briefly, the study recruited pregnant non-smoking women aged 18-39 years between October 2009 and July 2011 [44]. At 10-18 weeks gestation, 440 women were randomized to receive 4000 IU vitamin D plus a prenatal multivitamin containing $400 \mathrm{IU}$ vitamin D daily, and another 436 women were randomized to receive a placebo plus a prenatal multivitamin containing $400 \mathrm{IU}$ vitamin $\mathrm{D}$ daily. The primary endpoint was the composite outcome of asthma or recurrent wheezing by age 3 [45]. The institutional review boards at each participating institution and the Brigham and Women's Hospital approved protocols of the trial. All women provided written informed consent. The current analysis included children with plasma metabolomic data and $25(\mathrm{OH}) \mathrm{D}$ measurements at age 1 and age 3, respectively. Those without body mass index (BMI) measurements were further excluded since vitamin D is fat-soluble and adiposity may influence concentrations of certain metabolites, leading to final sample sizes of 450 at age 1 , and 407 at age 3 .

\subsection{Vitamin D Measurements}

Blood specimens were obtained from VDAART children at ages 1 and 3 years and stored following standard protocol [44]. Circulating 25(OH)D concentrations in the children's plasma samples were measured using the DiaSorin Liaison (DiaSorin) chemiluminescence immunoassay [46]. The interand intra-assay coefficients of variations were $11.2 \%$ and $8.1 \%$ respectively [45]. Here we report $25(\mathrm{OH}) \mathrm{D}$ measurements in nanograms per milliliter $(\mathrm{ng} / \mathrm{mL})$. To convert $25(\mathrm{OH}) \mathrm{D}$ concentrations from nanograms per milliliter $(\mathrm{ng} / \mathrm{mL})$ to nanomoles per liter $(\mathrm{nmol} / \mathrm{L})$, multiply by 2.496 .

\subsection{Metabolomics Data}

Plasma metabolites of VDAART children at ages 1 and 3 years were measured by Metabolon Inc. using both an untargeted approach and a targeted complex lipid panel. Untargeted metabolomics were profiled using ultrahigh-performance liquid chromatography coupled with tandem mass spectrometry $[47,48]$. The lipid panel was performed using flow injection and mass spectrometry analysis. To merge data from these two platforms, we scaled one data set to the other by a scaling factor, so that the medians of the quality control group within each data set were equivalent. We then imputed missing metabolite measures by replacement with half the lowest observed value in all samples for each metabolite. Metabolite intensities were log-10-transformed to improve their skewness. Relative quantification of 653 named and 181 unknown metabolites were processed, and 511 named metabolites with $\leq 10 \%$ missing across samples were included in this analysis. Details of the assays, data processing and quality control can be found in Supplementary File 1.

\subsection{Statistical Analysis}

Characteristics of VDAART children with metabolomic data at ages 1 and 3 are summarized in Table 1 , in both the total samples, and stratified by plasma $25(\mathrm{OH}) \mathrm{D}$ concentrations $(>30 \mathrm{ng} / \mathrm{mL}$ considered desirable/sufficient and $\leq 30 \mathrm{ng} / \mathrm{mL}$ considered insufficient) [3]. Linear regression models were used to assess the associations between each plasma metabolite (as independent variable) and plasma 25(OH)D concentrations (as dependent variable), cross-sectionally at ages 1 and 3 years respectively, adjusting for potential confounding factors. Plasma metabolite intensities were standardized by autoscaling [49] so that estimated $\beta$-coefficients were on comparable scales. We visually examined the distributions of $25(\mathrm{OH}) \mathrm{D}$ concentrations at ages 1 and 3 and calculated 
their skewness. Rosner's generalized extreme Studentized deviate many-outlier procedure was used to identify outliers in their distributions [25]. Sensitivity analyses excluding all outliers were then conducted to assess the robustness of our findings.

The selection of potential confounding factors was based on scientific knowledge and the literature a priori to statistical analysis, considering their causal relations with the metabolites and with plasma 25(OH)D concentrations. The primary models included sex (female, male), race (white, African American, others), ethnicity (Hispanic or Latino, not Hispanic or Latino), study site (Boston, St. Louis, San Diego), BMI (at ages 1 and 3 years respectively, continuous), and season of blood collection (four seasons separated by solstice and equinox). Having asthma or recurrent wheezing by age 3 (yes, no) was also included in the model as a potential effect modifier. These variables had no missing values within the analytical samples. We performed various sensitivity analyses to further evaluate the robustness of our findings, including the following modifications to the multivariable linear models: (1) removal of asthma or recurrent wheezing by age 3 as a covariate; (2) additional adjustment for maternal treatment group assignment (4400 IU/day or $400 \mathrm{IU} /$ day vitamin D supplementation). We additionally examined the differences in these characteristics comparing children included in the respective analytical samples at ages 1 and 3 with those not included.

We considered several methods to address multiple testing. We first used Bonferroni correction where only metabolite-25(OH)D associations with $P$-values $<9.78 \times 10^{-5}(0.05 / 511$ metabolites $)$ were considered significant, controlling the family-wise type I error rate at 0.05 . Because the Bonferroni correction is overly conservative in metabolomics studies where many metabolites are highly correlated, we also used the approach based on the effective number of independent tests (ENT) $[50,51]$. We computed ENT as the number of principal components needed to account for $80 \%$ of the total variance in metabolites, and termed the corresponding $P$-value threshold as ENT80 (calculated using Sidak correction $\left.1-(1-0.05)^{1 / E N T}\right)$. Metabolite-25(OH)D associations with $P$-values below ENT80 were declared significant. As a comparison, we also computed the false discovery rate (FDR) using the Benjamini and Hochberg $(\mathrm{BH})$ procedure [21], and the more conservative Benjamini and Yekutieli (BY) procedure for multiple testing under dependency [22]. We primarily report significant metabolite-25(OH)D associations common to the age 1 and age 3 analyses with the same direction of estimated effects.

We used the web-based tool MetaboAnalyst 4.0 to perform pathway analysis of the significant metabolites ( $P$-values below ENT80) [26]. All metabolites with Human Metabolome Database (HMDB) IDs were entered as the background list, and over-representation analysis was performed using the hypergeometric test, which tests if a particular group of compounds is represented more than expected by chance within the background list. In pathway topology analysis, we used relative betweenness centrality as the node importance measure, which generated pathway impact values (for more details see Supplementary File 1).

\subsection{Replication Analysis}

To replicate our findings in an independent cohort, we used data from the Childhood Asthma Management Program (CAMP), a randomized controlled trial to evaluate the effects of different treatments (inhaled corticosteroid, inhaled non-corticosteroid, or placebo) on lung growth in children aged 5 to 12 years with mild-to-moderate asthma (ClinicalTrials.gov Identifier: NCT00000575) [27,28]. Recruitment of CAMP participants occurred between December 1993 and September 1995, and 1041 children were randomized to participate in the trial for an average of 4.3 years [28]. Approval was obtained from the institutional review boards at each of the participating institutions of CAMP. Informed consent was obtained from the children's parents or guardians. Our replication analysis included children in CAMP with both serum 25(OH)D [52] and metabolomics data at baseline $(n=542)$ or end of the trial $(n=561)$, respectively. Metabolomic profiling in serum samples was conducted at The Broad Institute $[53,54]$ (details in Supplementary File 1). Equivalent models to the primary analyses in VDAART were employed for 501 named metabolites, with two adjustments: (1) we 
removed asthma status from the models since all children in CAMP were asthmatics, and (2) we adjusted for age at sampling since CAMP was not a birth cohort. The Bonferroni threshold of 0.05/number-of-metabolites-to-replicate was used for multiple testing correction. All analyses other than the pathway analysis were conducted in $\mathrm{R}$ version 3.6.0 [47]. We are committed to submitting our analytical dataset to a suitable publicly accessible repository, as such time as a repository designed for epidemiological metabolomic data becomes well-established.

\section{Conclusions}

In conclusion, the current study provides evidence for an association between higher plasma $25(\mathrm{OH}) \mathrm{D}$ concentrations with lower concentrations of multiple members in the metabolic cascade of linoleic acid, an essential n-6 PUFA, in children at ages 1 and 3 years. Since both vitamin D and n-6 PUFAs are involved in inflammatory processes, these relationships warrant further investigation in other study populations of similar age.

Supplementary Materials: The following are available online at http://www.mdpi.com/2218-1989/10/4/151/s1, Supplementary File 1 (Supplemental Figure S1. Number of metabolites passing their respective ENT80 thresholds when comparing results from the age 1 samples and those from the age 3 samples; Supplemental Figure S2. Illustration of metabolism of n-6 and n-3 PUFA. Boxes with dashed outline indicate the enzymes of desaturation, elongation, and $\beta$-oxidation involved in the cascade. Metabolites with a check mark were included in our analyses (the metabolomics platform could not distinguish between $\alpha$ - and $\gamma$-linolenic acid, so linolenic acid n-6 or n-3 was reported as one metabolite). Adapted from Patterson et al. and Schmitz et al.; Supplemental Figure S3. Boxplot and histogram of 25(OH)D levels in VDAART children at age 1 before and after exclusion of outlier identified by Rosner's outlier test; Supplemental Figure S4. Boxplot and histogram of 25(OH)D levels in VDAART children at age 3 before (upper panel) and after (lower panel) exclusion of outlier identified by Rosner's outlier test; Supplemental Figure S5. Plausible biological mechanism of how the active form of vitamin D, 1,25-dihydroxyvitamin D [1,25(OH)2D], may influence n-6 PUFA metabolism based on literature (ROS, reactive oxygen species); Pathway topology analysis details; Metabolomic profiling in the Vitamin D Antenatal Asthma Reduction Trial; Metabolomic profiling in the Childhood Asthma Management Program); Supplementary File 2 (Supplemental Table S1. Metabolites with $P$-values below the ENT80 threshold $\left(8.27 \times 10^{-4}\right)$ for their associations with plasma $25(\mathrm{OH}) \mathrm{D}$ levels in VDAART children at age 1; Supplemental Table S2. Metabolites with $P$-values below the ENT80 threshold $\left(9.67 \times 10^{-4}\right)$ for their associations with plasma 25(OH)D levels in VDAART children at age 3; Supplemental Table S3. Comparison of results from primary and sensitivity analysis altering model adjustment; Supplemental Table S4. Characteristics of children according to whether they are in analytical sample at age 1; Supplemental Table S5. Characteristics of children according to whether they are in analytical sample at age 3; Supplemental Table S6. Characteristics of CAMP participants at baseline who were included in replication analysis; Supplemental Table S7. Characteristics of CAMP participants at end of trial who were included in replication analysis; Supplemental Table S8. Replication analysis results in CAMP).

Author Contributions: Conceptualization, J.L.-S. and R.S.K.; methodology, M.H., R.S.K, P.K., S.H.C., K.L.-S., B.L.C., H.B., J.L.-S.; validation, R.S.K.; formal analysis, M.H.; data curation, J.L.-S., A.A.L., S.T.W.; writing-original draft preparation, M.H.; writing-review and editing, M.H., R.S.K, P.K., S.H.C., K.L.-S., B.L.C., H.B., A.A.L., S.T.W., J.L.-S.; supervision, J.L.-S.; funding acquisition, A.A.L., S.T.W., J.L.-S. All authors have read and agreed to the published version of the manuscript.

Funding: Metabolomics work was supported by the National Heart, Lung, and Blood Institute (NHLBI) grant R01HL123915 and R01HL141826. Efforts of M.H. and J.L-S. were supported by R01HL141826 from the NHLBI. Effort of R.S.K. was additionally supported by K01HL146980-01 from NHLBI. Efforts of J.L-S. and R.S.K. were also supported by W81XWH-17-1-0533 from the Department of Defense. Effort of P.K. was supported by P01HL132825 from the NHLBI. Effort of S.H.C. was supported by R01AR049880 from the National Institute of Arthritis and Musculoskeletal and Skin Diseases and U01HG008685 from the National Human Genome Research Institute. Effort of K.L-S. was supported by 5T32HL007427-34 from the NHLBI. Efforts of B.L.C. and H.B. were supported by private and public research funds all listed on www.copsac.com; The Lundbeck Foundation; Danish State Budget; Danish Council for Strategic Research; Danish Council for Independent Research and The Capital Region Research Foundation have provided core support for the Copenhagen Prospective Studies on Asthma in Childhood. Effort of A.A.L. was supported by R21HL089842 from the NHLBI. Effort of S.T.W. was supported by R01HL091528 from the NHLBI, UG3OD023268 from Office of The Director, National Institute of Health, and P01HL132825 from the NHLBI. The Vitamin D Antenatal Asthma Reduction Trial (ClinicalTrials.gov identifier: NCT00920621) was supported by grant U01HL091528 from NHLBI. Additional support was provided by grant U54TR001012 from the National Centers for Advancing Translational Sciences (NCATS) for participant visits at the Boston Medical Center. The Childhood Asthma Management Program (ClinicalTrials.gov Identifier: NCT00000575) was supported by contracts with the NHLBI: (NO1-HR-16044, NO1-HR-16045, NO1-HR-16046, NO1-HR-16047, NO1-HR-16048, NO1-HR-16049, NO1-HR-16050, NO1-HR-16051, and NO1-HR-16052) and by General Clinical Research Center grants from the National Center for Research Resources (M01RR00051, M01RR0099718-24, M01RR02719-14, and 
RR00036). The funders had no role in study design, data collection, data analysis and interpretation, decision to publish, or preparation of the manuscript.

Acknowledgments: We wish to thank all VDAART and CAMP participants, and all investigators and staff involved in collection and management of the data.

Conflicts of Interest: S.T.W. receives author royalties from UpToDate, and is unpaid advisor to Novartis Pharmaceuticals. A.A.L. receives author royalties from UpToDate. All other authors have declared that they have no conflict of interest.

\section{References}

1. Jiang, X.; Kiel, D.P.; Kraft, P. The genetics of vitamin D. Bone 2018, 126, 59-77. [CrossRef] [PubMed]

2. Cantorna, M.T.; Zhu, Y.; Froicu, M.; Wittke, A. Vitamin D status, 1,25-dihydroxyvitamin D3, and the immune system. Am. J. Clin. Nutr. 2004, 80, 1717S-1720S. [CrossRef] [PubMed]

3. Litonjua, A.A.; Weiss, S.T. Is vitamin D deficiency to blame for the asthma epidemic? J. Allergy Clin. Immunol. 2007, 120, 1031-1035. [CrossRef] [PubMed]

4. Sassi, F.; Tamone, C.; D'Amelio, P. Vitamin D: Nutrient, Hormone, and Immunomodulator. Nutrients 2018, 10, 1656. [CrossRef]

5. Hollis, B.W.; Wagner, C.L. Clinical review: The role of the parent compound vitamin D with respect to metabolism and function: Why clinical dose intervals can affect clinical outcomes. J. Clin. Endocrinol. Metab. 2013, 98, 4619-4628. [CrossRef]

6. Feng, H.; Xun, P.; Pike, K.; Wills, A.K.; Chawes, B.L.; Bisgaard, H.; Cai, W.; Wan, Y.; He, K. In utero exposure to 25-hydroxyvitamin $\mathrm{D}$ and risk of childhood asthma, wheeze, and respiratory tract infections: A meta-analysis of birth cohort studies. J. Allergy. Clin. Immunol. 2017, 139, 1508-1517. [CrossRef]

7. Pilz, S.; Verheyen, N.; Grubler, M.R.; Tomaschitz, A.; Marz, W. Vitamin D and cardiovascular disease prevention. Nat. Rev. Cardiol. 2016, 13, 404-417. [CrossRef]

8. Marquina, C.; Mousa, A.; Scragg, R.; de Courten, B. Vitamin D and cardiometabolic disorders: A review of current evidence, genetic determinants and pathomechanisms. Obes. Rev. 2019, 20, 262-277. [CrossRef]

9. Feldman, D.; Krishnan, A.V.; Swami, S.; Giovannucci, E.; Feldman, B.J. The role of vitamin D in reducing cancer risk and progression. Nat. Rev. Cancer 2014, 14, 342-357. [CrossRef]

10. Wolsk, H.M.; Chawes, B.L.; Litonjua, A.A.; Hollis, B.W.; Waage, J.; Stokholm, J.; Bonnelykke, K.; Bisgaard, H.; Weiss, S.T. Prenatal vitamin D supplementation reduces risk of asthma/recurrent wheeze in early childhood: A combined analysis of two randomized controlled trials. PLoS ONE 2017, 12, e0186657. [CrossRef]

11. Hibbs, A.M.; Ross, K.; Kerns, L.A.; Wagner, C.; Fuloria, M.; Groh-Wargo, S.; Zimmerman, T.; Minich, N.; Tatsuoka, C. Effect of Vitamin D Supplementation on Recurrent Wheezing in Black Infants Who Were Born Preterm: The D-Wheeze Randomized Clinical Trial. JAMA 2018, 319, 2086-2094. [CrossRef]

12. Jolliffe, D.A.; Greenberg, L.; Hooper, R.L.; Griffiths, C.J.; Camargo, C.A.; Kerley, C.P.; Jensen, M.E.; Mauger, D.; Stelmach, I.; Urashima, M.; et al. Vitamin D supplementation to prevent asthma exacerbations: A systematic review and meta-analysis of individual participant data. Lancet Respir. Med. 2017, 5, 881-890. [CrossRef]

13. Pfeffer, P.E.; Hawrylowicz, C.M. Vitamin D in Asthma: Mechanisms of Action and Considerations for Clinical Trials. Chest 2018, 153, 1229-1239. [CrossRef] [PubMed]

14. Fuhrer, T.; Zamboni, N. High-throughput discovery metabolomics. Curr. Opin. Biotechnol. 2015, 31, 73-78. [CrossRef] [PubMed]

15. Vogt, S.; Wahl, S.; Kettunen, J.; Breitner, S.; Kastenmuller, G.; Gieger, C.; Suhre, K.; Waldenberger, M.; Kratzsch, J.; Perola, M.; et al. Characterization of the metabolic profile associated with serum 25-hydroxyvitamin D: A cross-sectional analysis in population-based data. Int. J. Epidemiol. 2016, 45, 1469-1481. [CrossRef] [PubMed]

16. Nelson, S.M.; Panagiotou, O.A.; Anic, G.M.; Mondul, A.M.; Mannisto, S.; Weinstein, S.J.; Albanes, D. Metabolomics analysis of serum 25-hydroxy-vitamin D in the Alpha-Tocopherol, Beta-Carotene Cancer Prevention (ATBC) Study. Int. J. Epidemiol. 2016, 45, 1458-1468. [CrossRef]

17. Lasky-Su, J.; Dahlin, A.; Litonjua, A.A.; Rogers, A.J.; McGeachie, M.J.; Baron, R.M.; Gazourian, L.; Barragan-Bradford, D.; Fredenburgh, L.E.; Choi, A.M.K.; et al. Metabolome alterations in severe critical illness and vitamin D status. Crit. Care 2017, 21, 193. [CrossRef] 
18. Finkelstein, J.L.; Pressman, E.K.; Cooper, E.M.; Kent, T.R.; Bar, H.Y.; O’Brien, K.O. Vitamin D Status Affects Serum Metabolomic Profiles in Pregnant Adolescents. Reprod. Sci. 2015, 22, 685-695. [CrossRef]

19. Hasegawa, K.; Stewart, C.J.; Celedon, J.C.; Mansbach, J.M.; Tierney, C.; Camargo, C.A., Jr. Serum 25-hydroxyvitamin D, metabolome, and bronchiolitis severity among infants-A multicenter cohort study. Pediatr. Allergy Immunol. 2018, 29, 441-445. [CrossRef]

20. Berti, C.; Agostoni, C.; Davanzo, R.; Hypponen, E.; Isolauri, E.; Meltzer, H.M.; Steegers-Theunissen, R.P.; Cetin, I. Early-life nutritional exposures and lifelong health: Immediate and long-lasting impacts of probiotics, vitamin D, and breastfeeding. Nutr. Rev. 2017, 75, 83-97. [CrossRef]

21. Benjamini, Y.; Hochberg, Y. Controlling the False Discovery Rate: A Practical and Powerful Approach to Multiple Testing. J. R. Stat. Soc. Series B (Method.) 1995, 57, 289-300. [CrossRef]

22. Benjamini, Y.; Yekutieli, D. The control of the false discovery rate in multiple testing under dependency. Ann. Statist. 2001, 29, 1165-1188. [CrossRef]

23. Patterson, E.; Wall, R.; Fitzgerald, G.F.; Ross, R.P.; Stanton, C. Health implications of high dietary omega-6 polyunsaturated Fatty acids. J. Nutr. Metab. 2012, 2012, 539426. [CrossRef]

24. Schmitz, G.; Ecker, J. The opposing effects of n-3 and n-6 fatty acids. Prog. Lipid Res. 2008, 47, 147-155. [CrossRef] [PubMed]

25. Rosner, B. Percentage Points for a Generalized ESD Many-Outlier Procedure. Technometrics 1983, 25, 165-172. [CrossRef]

26. Chong, J.; Soufan, O.; Li, C.; Caraus, I.; Li, S.; Bourque, G.; Wishart, D.S.; Xia, J. MetaboAnalyst 4.0: Towards more transparent and integrative metabolomics analysis. Nucleic Acids Res. 2018, 46, W486-W494. [CrossRef]

27. The Childhood Asthma Management Program (CAMP): Design, rationale, and methods. Childhood Asthma Management Program Research Group. Control Clin. Trials 1999, 20, 91-120. [CrossRef]

28. Childhood Asthma Management Program Research, G.; Szefler, S.; Weiss, S.; Tonascia, J.; Adkinson, N.F.; Bender, B.; Cherniack, R.; Donithan, M.; Kelly, H.W.; Reisman, J.; et al. Long-term effects of budesonide or nedocromil in children with asthma. N. Engl. J. Med. 2000, 343, 1054-1063. [CrossRef]

29. Nandi, A.; Wadhwani, N.; Joshi, S.R. Vitamin D deficiency influences fatty acid metabolism. Prostaglandins Leukot. Essent. Fatty. Acids. 2019, 140, 57-63. [CrossRef]

30. Blighe, K.; Chawes, B.L.; Kelly, R.S.; Mirzakhani, H.; McGeachie, M.; Litonjua, A.A.; Weiss, S.T.; Lasky-Su, J.A. Vitamin D prenatal programming of childhood metabolomics profiles at age 3 y. Am. J. Clin. Nutr. 2017, 106, 1092-1099. [CrossRef]

31. Simopoulos, A.P. An Increase in the Omega-6/Omega-3 Fatty Acid Ratio Increases the Risk for Obesity. Nutrients 2016, 8, 128. [CrossRef]

32. Nandi, A.A.; Wadhwani, N.S.; Joshi, S.R. Altered metabolic homeostasis between vitamin D and long chain polyunsaturated fatty acids in preeclampsia. Med. Hypotheses. 2017, 100, 31-36. [CrossRef]

33. Das, U.N. Essential fatty acids: Biochemistry, physiology and pathology. Biotechnol. J. 2006, 1, 420-439. [CrossRef]

34. Harbige, L.S. Fatty acids, the immune response, and autoimmunity: A question of n- 6 essentiality and the balance between n-6 and n-3. Lipids 2003, 38, 323-341. [CrossRef]

35. Kriebitzsch, C.; Verlinden, L.; Eelen, G.; van Schoor, N.M.; Swart, K.; Lips, P.; Meyer, M.B.; Pike, J.W.; Boonen, S.; Carlberg, C.; et al. 1,25-dihydroxyvitamin D3 influences cellular homocysteine levels in murine preosteoblastic MC3T3-E1 cells by direct regulation of cystathionine beta-synthase. J. Bone Miner. Res. 2011, 26, 2991-3000. [CrossRef]

36. Signorello, M.G.; Pascale, R.; Leoncini, G. Effect of homocysteine on arachidonic acid release in human platelets. Eur. J. Clin. Invest. 2002, 32, 279-284. [CrossRef]

37. Li, B.; Gao, G.; Zhang, W.; Li, B.; Yang, C.; Jiang, X.; Tian, Y.; Liang, H. Metabolomics analysis reveals an effect of homocysteine on arachidonic acid and linoleic acid metabolism pathway. Mol. Med. Rep. 2018, 17, 6261-6268. [CrossRef]

38. Moreno, J.; Krishnan, A.V.; Swami, S.; Nonn, L.; Peehl, D.M.; Feldman, D. Regulation of prostaglandin metabolism by calcitriol attenuates growth stimulation in prostate cancer cells. Cancer Res. 2005, 65, 7917-7925. [CrossRef]

39. Wenzel, S.E. Arachidonic acid metabolites: Mediators of inflammation in asthma. Pharmacotherapy 1997, 17, 3S-12S. 
40. Calabrese, C.; Triggiani, M.; Marone, G.; Mazzarella, G. Arachidonic acid metabolism in inflammatory cells of patients with bronchial asthma. Allergy 2000, 55 (Suppl. 61), 27-30. [CrossRef]

41. Bisgaard, H.; Stokholm, J.; Chawes, B.L.; Vissing, N.H.; Bjarnadottir, E.; Schoos, A.M.; Wolsk, H.M.; Pedersen, T.M.; Vinding, R.K.; Thorsteinsdottir, S.; et al. Fish Oil-Derived Fatty Acids in Pregnancy and Wheeze and Asthma in Offspring. N. Engl. J. Med. 2016, 375, 2530-2539. [CrossRef]

42. Worobey, J. Physical activity in infancy: Developmental aspects, measurement, and importance. Am. J. Clin. Nutr. 2014, 99, 729S-733S. [CrossRef]

43. McKennan, C.; Ober, C.; Nicolae, D. Estimation and inference in metabolomics with non-random missing data and latent factors. ArXiv 2019, arXiv:1909.02644. Available online: https://arxiv.org/abs/1909.02644 (accessed on 1 April 2020).

44. Litonjua, A.A.; Lange, N.E.; Carey, V.J.; Brown, S.; Laranjo, N.; Harshfield, B.J.; O'Connor, G.T.; Sandel, M.; Strunk, R.C.; Bacharier, L.B.; et al. The Vitamin D Antenatal Asthma Reduction Trial (VDAART): Rationale, design, and methods of a randomized, controlled trial of vitamin D supplementation in pregnancy for the primary prevention of asthma and allergies in children. Contemp. Clin. Trials. 2014, 38, 37-50. [CrossRef]

45. Litonjua, A.A.; Carey, V.J.; Laranjo, N.; Harshfield, B.J.; McElrath, T.F.; O'Connor, G.T.; Sandel, M.; Iverson, R.E.; Lee-Paritz, A.; Strunk, R.C.; et al. Effect of Prenatal Supplementation With Vitamin D on Asthma or Recurrent Wheezing in Offspring by Age 3 Years: The VDAART Randomized Clinical Trial. JAMA 2016, 315, 362-370. [CrossRef]

46. Ersfeld, D.L.; Rao, D.S.; Body, J.J.; Sackrison, J.L., Jr.; Miller, A.B.; Parikh, N.; Eskridge, T.L.; Polinske, A.; Olson, G.T.; MacFarlane, G.D. Analytical and clinical validation of the $25 \mathrm{OH}$ vitamin $\mathrm{D}$ assay for the LIAISON automated analyzer. Clin. Biochem. 2004, 37, 867-874. [CrossRef]

47. Evans, A.M.; DeHaven, C.D.; Barrett, T.; Mitchell, M.; Milgram, E. Integrated, nontargeted ultrahigh performance liquid chromatography/electrospray ionization tandem mass spectrometry platform for the identification and relative quantification of the small-molecule complement of biological systems. Anal. Chem. 2009, 81, 6656-6667. [CrossRef]

48. Kelly, R.S.; McGeachie, M.J.; Lee-Sarwar, K.A.; Kachroo, P.; Chu, S.H.; Virkud, Y.V.; Huang, M.; Litonjua, A.A.; Weiss, S.T.; Lasky-Su, J. Partial Least Squares Discriminant Analysis and Bayesian Networks for Metabolomic Prediction of Childhood Asthma. Metabolites 2018, 8. [CrossRef]

49. Van den Berg, R.A.; Hoefsloot, H.C.; Westerhuis, J.A.; Smilde, A.K.; van der Werf, M.J. Centering, scaling, and transformations: Improving the biological information content of metabolomics data. BMC Genom. 2006, 7, 142. [CrossRef]

50. Alonso, A.; Marsal, S.; Julia, A. Analytical methods in untargeted metabolomics: State of the art in 2015. Front Bioeng. Biotechnol. 2015, 3, 23. [CrossRef]

51. Demirkan, A.; van Duijn, C.M.; Ugocsai, P.; Isaacs, A.; Pramstaller, P.P.; Liebisch, G.; Wilson, J.F.; Johansson, A.; Rudan, I.; Aulchenko, Y.S.; et al. Genome-wide association study identifies novel loci associated with circulating phospho- and sphingolipid concentrations. PLoS Genet 2012, 8, e1002490. [CrossRef] [PubMed]

52. Brehm, J.M.; Schuemann, B.; Fuhlbrigge, A.L.; Hollis, B.W.; Strunk, R.C.; Zeiger, R.S.; Weiss, S.T.; Litonjua, A.A.; Childhood Asthma Management Program Research, G. Serum vitamin D levels and severe asthma exacerbations in the Childhood Asthma Management Program study. J. Allergy Clin. Immunol. 2010, 126, 52-58.e55. [CrossRef] [PubMed]

53. Kelly, R.S.; Chawes, B.L.; Blighe, K.; Virkud, Y.V.; Croteau-Chonka, D.C.; McGeachie, M.J.; Clish, C.B.; Bullock, K.; Celedon, J.C.; Weiss, S.T.; et al. An Integrative Transcriptomic and Metabolomic Study of Lung Function in Children With Asthma. Chest 2018, 154, 335-348. [CrossRef] [PubMed]

54. Paynter, N.P.; Balasubramanian, R.; Giulianini, F.; Wang, D.D.; Tinker, L.F.; Gopal, S.; Deik, A.A.; Bullock, K.; Pierce, K.A.; Scott, J.; et al. Metabolic Predictors of Incident Coronary Heart Disease in Women. Circulation 2018, 137, 841-853. [CrossRef]

(C) 2020 by the authors. Licensee MDPI, Basel, Switzerland. This article is an open access article distributed under the terms and conditions of the Creative Commons Attribution (CC BY) license (http://creativecommons.org/licenses/by/4.0/). 